\title{
Citotoxicidad de soluciones recomendadas para el almacenamiento de dientes avulsionados en cultivo con células del ligamento periodontal
}

\author{
Galia Cruz-Durán, ${ }^{1}$ Raúl Ortiz-Daza, ${ }^{1}$ Jacinto Armando Díaz-Acevedo, ${ }^{1}$ Benjamín Sánchez-Trocino, ${ }^{1}$ \\ Ma. Concepción Arenas-Arrocena ${ }^{2}$ y René García-Contreras ${ }^{2}$ \\ ${ }^{\top}$ Área de Cirugía Oral y Maxilofacial; ${ }^{2}$ Área de Nanoestructuras y Biomateriales. Escuela Nacional de Estudios Superiores, Unidad León, Universidad \\ Nacional Autónoma de México, León, Guanajuato, México
}

\begin{abstract}
Resumen
Introducción: El medio de almacenamiento de los dientes avulsionados hasta su reimplante es vital para conservar los fibroblastos del ligamento periodontal humano (HPLF). Objetivo: Comparar el efecto citotóxico para conservar los HPLF de la leche y la solución isotónica para almacenamiento de dientes avulsionados. Método: Se realizó subcultivo de fibroblastos del

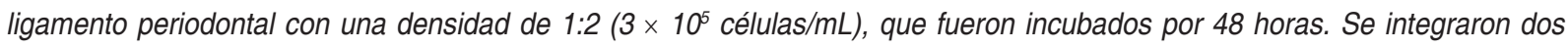
grupos de células, que se colocaron en leche y solución isotónica durante 24 horas a $5 \%$ de $\mathrm{CO}_{2}$, a $37^{\circ} \mathrm{C}$ y $95 \%$ de humedad. El número de células viables fue determinado por colorimetría rápida por reducción de MTT y actividad mitocondrial. Los datos fueron sometidos a pruebas de normalidad de Shapiro-Wilk, $t$ de Student y $t$ de Student pareada (significación de 0.05). Resultados: Las células expuestas a la leche por 24 horas mostraron citotoxicidad estadísticamente significativa a concentraciones de 0.09, 0.39, 0.78, 1.56, 3.125, 6.25 y 50 \%. Los HPLF expuestos a solución isotónica no mostraron reducción significativa del número de células a concentraciones de 25 y 50 \%. Conclusión: La solución isotónica parece mejor para el almacenamiento de HPLF en 24 horas, comparada con la leche entera.
\end{abstract}

PALABRAS CLAVE: Avulsión dental. Reimplantación dental. Medio de cultivo. Solución isotónica. Leche.

\begin{abstract}
Introduction: The medium for avulsed teeth storage until their reimplantation is key to the preservation of human periodontal ligament fibroblasts (HPLF). Objective: Our purpose was to compare the cytotoxic effect of milk and isotonic solution, used for the storage of avulsed teeth, on the preservation of HPLF. Method: A subculture of periodontal ligament fibroblasts was carried out with a density of 1:2 $\left(3 \times 10^{5} \mathrm{cell} / \mathrm{s} / \mathrm{mL}\right)$ and was incubated for 48 hours. The cells were divided in two groups, which were placed either in milk or isotonic solution for 24 hours at $5 \% \mathrm{CO}_{2}, 37{ }^{\circ} \mathrm{C}$ and $95 \%$ humidity. The number of viable cells was determined with a colorimetric fast assay by the reduction of MTT and mitochondrial activity. Data were processed with the Shapiro-Wilk normality test, Student's t-test and paired Student's t-test (with significance set at 0.05). Results: The cells exposed to milk for 24 hours showed statistically significant cytotoxicity at concentrations of $0.09,0.39,0.78,1.56,3.125,6.25$ and $50 \%$. HPLFs exposed to isotonic solution showed no significant reduction in the number of cells at concentrations of 25 and $50 \%$. Conclusion: Isotonic solution appears to be better for HPLF 24-hour storage in comparison with whole milk.
\end{abstract}

KEY WORDS: Tooth avulsion. Tooth reimplantation. Culture medium. Isotonic solutions. Milk.

Correspondencia:

René García-Contreras

E-mail: dentist.garcia@gmail.com
Fecha de recepción: 01-12-2016

Fecha de aceptación: 24-01-2018

DOI://dx.doi.org/10.24875/GMM.18003056
Gac Med Mex. 2018;154:217-221

Disponible en PubMed

www.gacetamedicademexico.com 


\section{Introducción}

De acuerdo con la clasificación de trauma dental de la Organización Mundial de la Salud, la avulsión dental es el desplazamiento completo de un diente de su alvéolo. ${ }^{1}$ Se ha reportado una incidencia de $16 \%$ entre todos los traumas dentales de dentición permanente y de 7 a $21 \%$ en cuanto a la dentición temporal. La avulsión es una lesión dental grave y su pronóstico varía dependiente del procedimiento inmediato después del accidente. Reimplantar el diente en el sitio que le corresponde es uno de los tratamientos de elección, aun cuando no siempre se puede llevar a cabo de forma inmediata. ${ }^{2}$

Diversos estudios coindicen en que la reimplantación dental tiene un mejor pronóstico cuanto menos tiempo permanezca el diente fuera del alveolo y el ligamento periodontal se conserve íntegro. El pronóstico mejora considerablemente $(41 \%)$ cuando los dientes aún cuentan con un ápice abierto, lo que aumenta la incidencia para la revascularización de la pulpa. ${ }^{3}$ Las células del ligamento periodontal tienen constante suministro de sangre, $\mathrm{pH}$ de 7.2 , osmolaridad de 280 a 300 mOsm, así que cuando el diente ha sido desalojado de su alveolo, estas células comienzan a morir en menos de 15 minutos y en menos de una a dos horas han muerto suficiente número de células del ligamento periodontal, lo que disminuye drásticamente la perduración y éxito del reimplante. El resultado de la necrosis del ligamento periodontal se observa a largo plazo con la resorción radicular dental y anquilosis.

La supervivencia del reimplante depende de mantener íntegras las células que conforman el ligamento periodontal. Para ello es crucial mantener el diente inmerso en un medio líquido; se ha reportado que la leche, el agua o la saliva son óptimas para la preservación; el almacenamiento en ellas puede incrementar el tiempo de espera hasta por 24 horas después de la avulsión, para la posterior manipulación y reimplantación. ${ }^{3,4}$ Cuando el diente avulsionado se reimplanta después de 15 minutos, las células del ligamento periodontal dañadas causan resorción parcial. Además, un reimplante con más de 30 minutos puede causar daño irreversible a las células, un reimplante que se retarda más de 60 minutos en condiciones secas puede causar necrosis del ligamento periodontal (LP), provocando resorción extensa de la raíz. Los mejores pronósticos se obtienen cuando el tiempo extraalveolar no excede los cinco minutos. ${ }^{5}$

El medio de almacenamiento debe tener la capacidad de preservar la vitalidad de las células y su capacidad de adherencia, así como estar rápidamente disponible en el momento de la avulsión. Tanto la osmolaridad fisiológica como el pH son determinantes para preservar la viabilidad de células del LP. El crecimiento celular ocurre en un rango de 230 a 400 mOsm, sin embargo, el crecimiento óptimo oscila entre 290 y 330 mOsm; el pH es de 6.6 a 7.8 y el rango ideal es de 7.2 a $7.4 .^{6}$

La leche ha sido recomendada como un medio para almacenar un diente avulsionado porque tiene osmolaridad compatible (220 mOsm) con la de las células del ligamento periodontal, además de que está ampliamente disponible, sin embargo, carece de los metabolitos necesarios y la glucosa para la fisiología normal de la célula. La leche mantiene las células del ligamento periodontal vitales de una a tres horas. Se ha demostrado que las células que fueron secadas por 20 a 30 minutos y después puestas en leche por 45 minutos tuvieron mucha menos vitalidad que las que fueron secadas por solo 10 minutos. ${ }^{7}$ Las células del LP secadas con aire por 60 minutos o más y que después fueron colocadas en leche mostraron una vitalidad casi nula, lo cual demuestra la capacidad de la leche para mantener la presión osmótica para las células del LP, pero no su habilidad para reconstituir el metabolismo de las células o restaurar su vitalidad. Solo la leche fría puede conservar la habilidad de las células del LP para proliferar. ${ }^{3,8}$

La solución isotónica utilizada fue una bebida rehidratante, energizante, isotónica de uso común, con diversos componentes, que pudieran tener capacidad para almacenar las células del ligamento periodontal humano (HPLF): cloruro de sodio, cloruro de potasio, cloruro de calcio, cloruro de magnesio, lactato de sodio y glucosa, sin embargo, su pH de 4.5 podría significar una desventaja importante si se compara con otras soluciones como la leche.

El objetivo del presente estudio fue comparar el efecto citotóxico en la conservación de las HPLF de la leche y una solución isotónica, recomendadas para almacenamiento de dientes avulsionados, mediante pruebas de viabilidad celular con un ensayo de colorimetría rápida por reducción de MTT y actividad mitocondrial.

\section{Método}

\section{Cultivo celular primario}

Las células del ligamento periodontal (HPLF) se obtuvieron por medio de biopsia del tejido periodontal a partir de la extracción dentaria de terceros molares 
erupcionados libres de caries o infección, de dos pacientes de 18 y 25 años de edad, con la firma previa del consentimiento informado y la autorización del comité de bioética de la Escuela Nacional de Estudios Superiores Unidad León, Universidad Nacional Autónoma de México, León, Guanajuato, México.

Los dientes extraídos con el tejido obtenido se suspendieron en medio Alpha-MEM ${ }^{\circledR}$ (Life Technologies, Gibco, Carlsbad, CA, EE. UU.) adicionado con suero fetal bovino (FBS, Life Technologies, Gibco, Carlsbad, CA, EUA) a $20 \%, 100000 \mathrm{UI} / \mathrm{mL}$ de penicilina $\mathrm{G}$ y $100 \mu \mathrm{g} / \mathrm{mL}$ de sulfato de estreptomicina ${ }^{\circledR}$ (Life Technologies, Gibco, Carlsbad, CA, EE. UU.).

Los tejidos se seccionaron en pequeñas porciones con una hoja de bisturí número 15. Los explantes fueron colocados en cajas de cultivo de $100 \mathrm{~mm}$ e incubados a $37{ }^{\circ} \mathrm{C}$, con una atmósfera de $5 \%$ de $\mathrm{CO}_{2}$ durante dos semanas para su crecimiento exponencial, con cambios del medio de cultivo primero al séptimo día y posteriormente cada tercer día. El crecimiento celular se obtuvo como cultivo primario con un nivel doble de población (PDL, population doubling level) de cero. Cuando la densidad celular fue de $80 \%$, los subcultivos se realizaron al desprender del plato de cultivo las células con $1 \mathrm{~mL}$ de $0.25 \%$ de tripsina- $0.025 \%$ EDTA-2Na ${ }^{\circledR}$ (Life Technologies, Gibco, Carlsbad, CA, EE. UU.) en PBS(-) y se incubaron durante cinco minutos a $37^{\circ} \mathrm{C}$; se comprobó el desprendimiento observando en el microscopio las células que circulaban en la caja de cultivo. Los subcultivos se realizaron a una concentración de 1:3 y el medio de cultivo (DMEM + 10\% de FBS) se remplazó cada tercer día. Los fibroblastos del ligamento periodontal tienen un tiempo de vida in vitro de 30 PDL (número acumulado).

\section{Ensayo de citotoxicidad}

Se realizaron subcultivos con una densidad de $1: 2\left(3 \times 10^{5}\right.$ células $/ \mathrm{mL}$ ) en platos de 96 pocillos (Ultra $\mathrm{Cruz}^{\circledR}$, Santa Cruz Biotechnology, Hamburgo, Alemania) y fueron incubados por 48 horas a $5 \%$ de $\mathrm{CO}_{2}$ a $37{ }^{\circ} \mathrm{C}$ y $95 \%$ de humedad. Se retiró todo el medio de cultivo y se colocaron en nuevo medio de cultivo fresco. La leche entera (Pasteurizadora León, León, Guanajuato, México) y la solución isotónica (Electrolit, Laboratorios Pisa, Guadalajara, Jalisco, México) fueron inoculadas a diferentes concentraciones, de 0 a $50 \%$. Las células fueron incubadas durante 24 horas a la misma temperatura en las mismas condiciones. La viabilidad celular fue determinada por el ensayo de colorimetría rápida por reducción de formazán de MTT $^{\circledR}$ (Sigma-Aldrich, Toluca, México).
Fueron disueltos en medio de cultivo DMEM $0.2 \mathrm{mg} / \mathrm{mL}$; las células fueron incubadas durante cuatro horas a $37^{\circ} \mathrm{C}$ y se retiró el medio de cultivo hasta disolver cristales con dimetilsulfóxido (DMOS, Karal, León, México). La viabilidad celular de la curva dosis-respuesta fue determinada y analizada en espectrofotómetro de microplaca a $570 \mathrm{~nm}$. Los ensayos se realizaron por duplicado, 16 para cada solución.

\section{Análisis estadístico}

El promedio, desviación estándar, porcentaje y concentración de citotoxicidad media $\left(\mathrm{CC}_{50}\right)$ fueron calculados a partir de la curva de dosis-respuesta. Los datos fueron sometidos a pruebas de normalidad de Shapiro-Wilk, t de Student y t de Student pareada. La significación estadística fue fijada con $p<0.05$, con un coeficiente de confiabilidad de $95 \%$.

\section{Resultados}

Se observó el comportamiento de las HPLF en ambas soluciones y se investigó la citotoxicidad de estas a diferentes concentraciones. Las células expuestas a la leche por 24 horas mostraron citotoxicidad estadísticamente significativa, con $p<0.01$ a concentraciones de $0.09 \%, 0.39 \%, 0.78 \%, 1.56 \%, 3.125 \%$, $6.25 \%$ y $50 \%$, destacando el $\mathrm{CC}_{50}=46.82 \%$.

El grupo de HPLF expuestas a la solución isotónica no mostró diferencias significativas, con $p>0.05 a$ concentraciones de 50 y $25 \%$, sin embargo, estas concentraciones no mostraron disminución de la viabilidad celular por debajo de $80 \%$, mostrando efectos citoestables en el cultivo. Al compararlas se encontraron diferencias estadísticamente significativas en HPLF: en las concentraciones de 12.5 y $25 \%$ se registró $p<0.05$ y en el resto, $p<0.01$ (Tabla 1 y Figura 1 ).

\section{Discusión}

Se ha descrito que el medio de almacenamiento ideal debe tener características biológicas para preservar la vitalidad de las células y su capacidad de adherencia, así como estar disponible en el momento de la avulsión. Tanto la osmolalidad fisiológica como el $\mathrm{pH}$ son determinantes para preservar la viabilidad de las células del LP. El crecimiento celular ocurre en un rango de 230 a $400 \mathrm{mOsm}$, sin embargo, es óptimo en un rango de 290 a 330 mOsm; el pH es de 6.6 a 7.8 y el rango ideal es de 7.2 a $7.4 .^{2}$

Se han investigado diferentes soluciones que podrían presentar características convenientes para el 


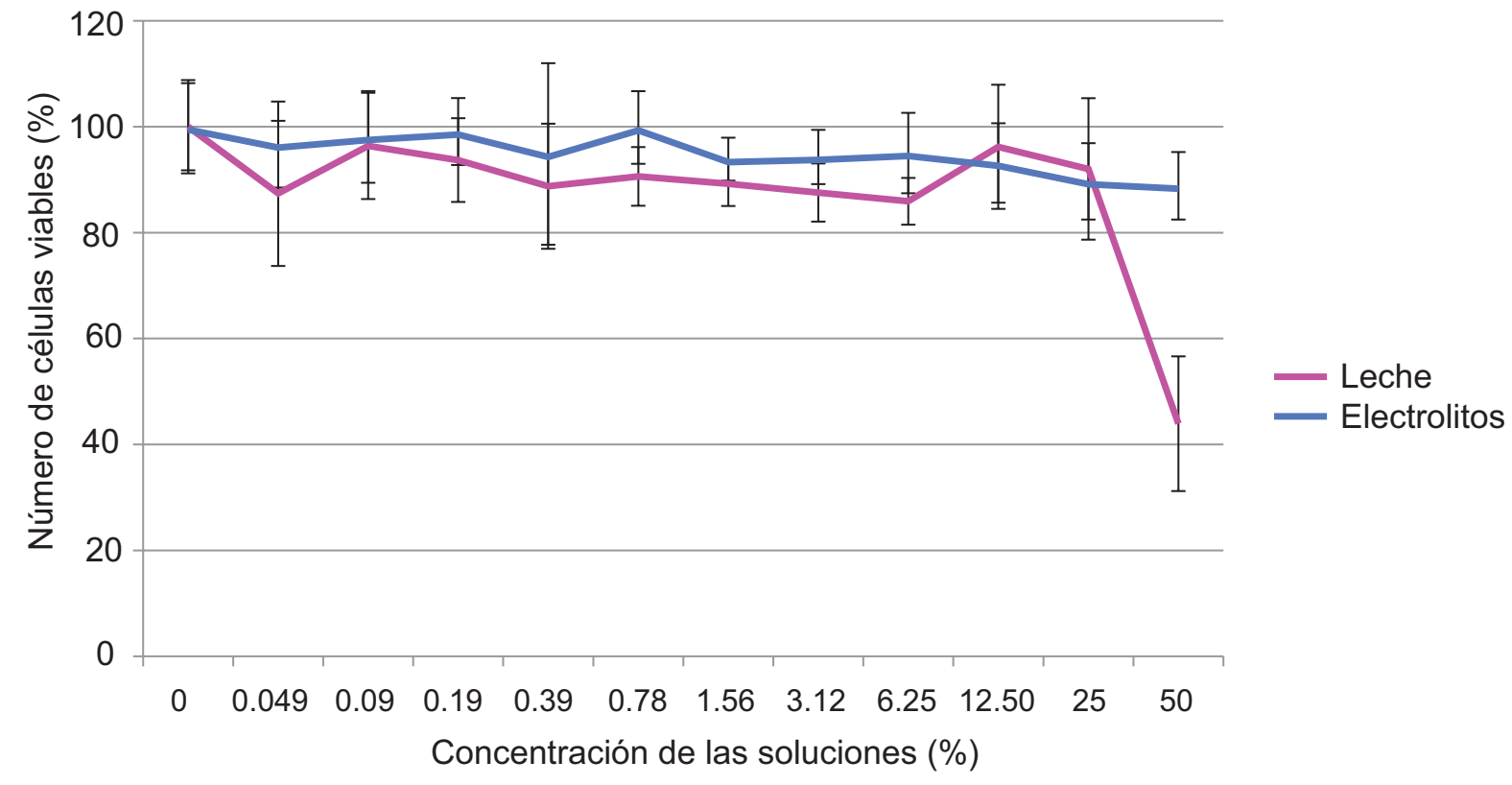

Figura 1. Efecto sobre la viabilidad de las células del ligamento periodontal, de la leche y la solución isotónica a diferentes concentraciones. Se puede observar mayor citotoxicidad de la leche a concentraciones mayores de $C C_{50}$, con reducción de la viabilidad celular.

Tabla 1. Viabilidad celular (\%) del contacto de una solución isotónica y de la leche en cultivo con fibroblastos del ligamento periodontal humano (HPLF)

\begin{tabular}{lccc}
\hline Dosis (\%) & Solución isotónica (\%) & Leche (\%) & $\begin{array}{c}\mathbf{p} \\
\text { (t de Student) }\end{array}$ \\
\hline 0 & 100 & 100 & \\
0.09 & $96.63 \pm 8.12$ & $87.41 \pm 13.7^{* *}$ & $<0.01$ \\
0.19 & $98.07 \pm 8.65$ & $96.37 \pm 10.03$ & $<0.01$ \\
0.39 & $99.09 \pm 6.32$ & $93.70 \pm 7.9^{* *}$ & $<0.01$ \\
0.78 & $94.85 \pm 17.14$ & $88.76 \pm 11.8^{* *}$ & $<0.01$ \\
1.56 & $99.85 \pm 6.86$ & $90.61 \pm 5.53^{* *}$ & $<0.01$ \\
3.125 & $93.87 \pm 4.05$ & $89.21 \pm 4.18^{* *}$ & $<0.01$ \\
6.25 & $95.02 \pm 7.59$ & $85.91 \pm 4.41^{* *}$ & $<0.01$ \\
12.5 & $93.15 \pm 7.5$ & $96.20 \pm 11.72$ & $<0.05$ \\
25 & $89.68 \pm 7.21^{*}$ & $92.03 \pm 13.3$ & $<0.05$ \\
50 & $88.84 \pm 6.37^{*}$ & $43.9 \pm 12.7^{* *}$ & $<0.01$ \\
\hline
\end{tabular}

Las diferencias entre ambas soluciones se muestran como media \pm desviación estándar $(n=16)$. Las columnas representan la t pareada de las diferentes concentraciones. ${ }^{*} p<0.05,{ }^{* *} p<0.01$

almacenamiento de HLPF; las que han mostrado mejor capacidad para preservar la viabilidad celular son Custodiol $^{\circledR}$, un líquido para transporte de órganos, y la solución salina balanceada de Hank (HBSS). ${ }^{9 \cdot 14} \mathrm{Sin}$ embargo, debido a su baja disponibilidad y a la dificultad para encontrarla, se han investigado otras soluciones que pudieran ser buenas opciones para el almacenamiento de dientes avulsionados. De acuerdo con Krasner et al., ${ }^{11}$ Sigalas et al..$^{13}$ y Özan, ${ }^{14}$ la leche es una solución adecuada para el almacenamiento de fibroblastos del ligamento periodontal (HLPF) debido a su osmolaridad y pH, además de su fácil disponibilidad en el sitio de la lesión. Otras soluciones han sido probadas, ${ }^{14-18}$ como el Gatora$\mathrm{de}^{\circledast,},{ }^{15}$ debido a que su pH ácido mostró alta capacidad para producir apoptosis celular, y el líquido de lentes contacto, ${ }^{14}$ que no mostró diferencias significativas con la HBSS y la leche; extracto de té verde, ${ }^{16}$ eficaz para preservar la viabilidad celular del ligamento periodontal por 24 horas y que además demostró efecto antiinflamatorio, antioxidante y anticarcinogénico; el agua de coco demostró ser mejor en la preservación de LP en comparación con la HBSS y la leche. ${ }^{17}$

La solución isotónica utilizada tiene un $\mathrm{pH}$ de 4.5, y una osmolaridad de $116 \mathrm{mOsm}$. Al investigar la capacidad para producir citotoxicidad a 24 horas a concentraciones de 0 a $50 \%$ no se encontró ninguna diferencia significativa en la reducción de la viabilidad celular. Sin embargo, es necesario realizar otras investigaciones ya que hasta el momento ningún otro autor ha reportado su potencial aplicación con dicha solución. Como referencia, se ha probado la solución fisiológica, con la que, según Caglar, ${ }^{18}$ se observaron resultados similares a los de la leche y la HBSS a 30 y 45 minutos. 
En el presente estudio, al realizar la comparación de la solución isotónica con la leche se encontró que la primera es significativamente mejor en la preservación celular a cualquier concentración; se observaron diferencias significativas en cuanto al grupo control únicamente a concentraciones de 50 y $25 \%$, probablemente por los electrolitos presentes en esta solución, necesarios para la preservación de los HPLF, sin embargo, esto es controversial debido a que su osmolaridad y pH son más bajos a los recomendados en la literatura. Es importante señalar que la solución isotónica es de costo bajo y está disponible en diversos comercios y al alcance de toda la población.

Debido a que los resultados respecto a la leche y la solución isotónica no coinciden con los de investigaciones previas, ni con los esperados por las características biológicas de ambas soluciones, es necesario realizar investigaciones orientadas a comprobar los efectos de una y otra con variabilidad no solo en las concentraciones sino también en el tiempo de almacenamiento de los HPLF antes de sufrir muerte celular irreversible o expresión de citocitas que puedan interferir en la vitalidad de las células periodontales, aspecto fundamental posterior a una avulsión dental.

\section{Conclusión}

La leche ha sido considerada la solución ideal para el almacenamiento de los dientes avulsionados, por sus características biológicas y su disponibilidad en el mercado. En este estudio se demostró que una solución isotónica de alta disponibilidad en México parece tener mejores resultados en cuanto al almacenamiento de HPLF en un tiempo de 24 horas.

\section{Bibliografía}

1. Andreasen JO. Effect of extra-alveolar period and storage media upon periodontal and pulp healing after replantation of mature permanent incisors in monkeys. Int J Oral Surg. 1981;10(1):43-53.

2. Gopikrishna V, Baweja PS, Venkateshbabu N, Thomas T, Kandaswamy D. Comparison of coconut water, propolis, HBSS, and milk on PDL cell survival. J Endod. 2008;34(5):587-589.

3. Petrovic B, Marković D, Peric T, Blagojevic D. Factors related to treatment and outcomes of avulsed teeth. Dent Traumatol. 2010;26(1):52-59.

4. Khademi AA, Saei S, Mohajeri MR, Mirkheshti N, Ghassami F, Alavi SA, et al. A new storage medium for an avulsed tooth. J Contemp Dent Pract. 2008:9(6):25-32.

5. Martin MP, Pileggi R. A quantitative analysis of Propolis: a promising new storage media following avulsion. Dent Traumatol. 2004;20(2):85.89.

6. Moreira-Neto JJ, Gondim JO, Raddi MSG, Pansani CA. Viability of human fibroblasts in coconut water as storage medium. Int Endod J. 2009;42(9):827-830.

7. Goswami M, Chaitra TR, Chaudhary S, Manuja N, Sinha A. Strategies for periodontal ligament cell viability: An overview. J Conserv Dent. 2011;14(3):215-220.

8. Hiltz J, Trope M. Vitality of human lip fibroblasts in milk, Hanks balanced salt solution and Viaspan storage media. Endod Dent Traumatol. 1991;7(2):69-72.

9. Thomas T, Gopikrishna V, Kandaswamy D. Comparative evaluation of maintenance of cell viability of an experimental transport media "coconut water" with Hank's balanced salt solution and milk, for transportation of an avulsed tooth: an in vitro cell culture study. J Conserv Dent. 2008;11(1):22-29.

10. Alaçam $T$, Görgül $G$, Omürlü $H$, Can $M$. Lactate dehydrogenase activity in periodontal ligament cells stored in different transport media. Oral Surg Oral Med Oral Pathol Oral Radiol Endod. 1996;82(3):321-323.

11. Krasner P, Rankow $H$. New philosophy for the treatment of avulsed teeth. Oral Surg Oral Med Oral Pathol Oral Radiol Endod. 1995;79(5):616-623.

12. Poi WR, Salineiro SL, Miziara FV, Miziara EV. Education as a means of enhancing the prognosis of tooth replantation. Rev Assoc Paul Cir Dent. 1999;53:474-479.

13. Sigalas E, Regan JD, Kramer PR, Witherspoon DE, Opperman LA. Survival of human periodontal ligament cells in media proposed for transport of avulsed teeth. Dent Traumatol. 2004;20(1):21-28.

14. Ozan F, Polat ZA, Er K, Ozan U, Değer O. Effect of propolis on survival of periodontal ligament cells: new storage media for avulsed teeth. J Endod. 2007;33(5):570-573.

15. Chamorro MM, Regan JD, Opperman LA, Kramer PR. Effect of storage media on human periodontal ligament cell apoptosis. Dent Traumatol. 2008;24(1):11-16.

16. Hwang JY, Choi SC, Park JH, Kang SW. The use of green tea extract as a storage medium for the avulsed tooth. J Endod. 2011;37(7):962-967.

17. Gopikrishna V, Thomas T, Kandaswamy D. A quantitative analysis of coconut water: a new storage media for avulsed teeth. Oral Surg Oral Med Oral Pathol Oral Radiol Endod. 2008;105(2):61-65.

18. Çaglar E, Sandalli N, Kuscu OO, Durhan MA, Pisiriciler R, Caliskan EA, et al. Viability of fibroblasts in a novel probiotic storage media. Dent Traumatol. 2010;26(5):383-387. 